\title{
ANALYSIS \\ Cardioprotection from metabolism to molecules to certainties
}

\author{
Lionel H Opie
}

Starting millions of years ago, the heart developed metabolic and molecular cardioprotective paths. The concept of metabolic protection includes the recent successful early provision of glucose-insulin-potassium (GIK) to patients with acute coronary syndromes in the ambulance to inhibit high harmful free-fatty acid levels. Molecular cardioprotective pathways also developed in primeval times. The 2 major paths are the RISK (Reperfusion
Injury Salvage Kinases) path and the SAFE (Survival Activating Factor Enhancement) path, on which our group in Cape Town has focused. These paths help to lessen ischaemic-perfusion damage, and may, hypothetically, also be activated by intense exercise.

S Afr Med J 2012;102(6):491-492.
The early cardiac physiologists discovered that depriving the heart of its blood supply led to an acceleration of glycolysis which could provide anaerobic energy. Richard Bing ${ }^{1}$ in the 1950s used the novel tool of coronary sinus catheterisation to study the energy sources of human heart muscle in patients with heart failure. He showed that for its energy sources the heart uses mostly fatty acids and to a lesser extent glucose. Circulating free-fatty acids (FFA) could inhibit myocardial glucose oxidation. ${ }^{2}$ In 1962 Sodi-Pallares et al. ${ }^{3}$ launched the concept of metabolic therapy using glucose-insulin-potassium (GIK) solutions that reduced acute electrocardiographic signs of ischaemic damage.

The mechanism whereby GIK provides benefit is in part by reducing the toxic high FFA levels that are found in early acute myocardial infarction (AMI) as a result of major catecholamine stimulation with acute adipose tissue lipolysis (Fig. 1). ${ }^{4,5}$ In heart failure (HF), beta-blockade and GIK also reduce circulating FFA, while the newer drugs trimetazidine and ranolazine act metabolically to improve the condition of patients with ischaemia or HF. ${ }^{6}$

\section{Metabolic therapy must be given early}

Almost all of the prior GIK studies for patients with acute coronary syndromes (ACS) started infusions far too late after the onset of symptoms. During the critical first hour, GIK infusions could potentially reduce major energy depletion. Crucial experimental support for this concept came from relevant work at the University of Cape Town (UCT) supported by the Chris Barnard Fund, thus supporting the rationale for the positive IMMEDIATE study in which GIK was infused by paramedics to patients in the prehospital emergency ambulance setting. ${ }^{8}$ Started immediately after the onset of symptoms, and continued thereafter, GIK reduced by $40 \%$ the rate of the combined cardiovascular endpoint, cutting in-hospital mortality or cardiac arrest by half, besides reducing infarct size measured at 30 days. $^{8}$

Professor Lionel Opie is Emeritus Director of the Hatter Institute for Cardiovascular Research in Africa, Department of Medicine, University of Cape Town and Groote Schuur Hospital, Cape Town.

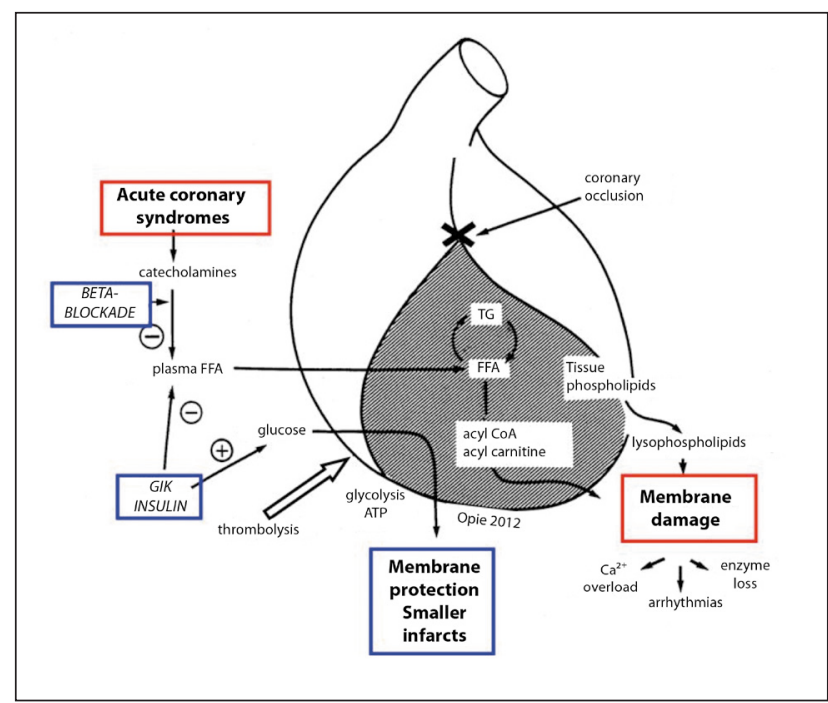

Fig. 1. Metabolic cardioprotection during acute coronary syndromes (ACS) hinges on reduction of circulating free-fatty acids (FFA) both by betablockade and by infusion of glucose-insulin-potassium (GIK). ${ }^{8}$ Thereby protective glycolytic metabolism by the ischaemic tissue is promoted. The harm of FFA is exerted by increasing tissue fatty acids acyl CoA and carnitine, thereby promoting membrane damage and lethal arrhythmias. $T G=$ tissue triglycerides.

\section{Molecular cardioprotection}

The extraordinary complexity of the molecular protective pathways must, like the metabolic paths, have evolved millions of years ago when rapid cardioprotection was required after the hyperadrenergic stresses and blood losses experienced when hunting and escaping from wild animals. ${ }^{9}$

Today these paths can be brought into action during prompt therapy for acute coronary occlusion by rapid reperfusion, as in AMI. Although saving many cells otherwise threatened with ischaemic cell death, rapid reperfusion kills a significant percentage of cells that could have been saved by the appropriate intervention. Indeed, the time has come to take reperfusion injury seriously! ${ }^{10}$

Reperfusion damage, with the sudden return of oxygen and reversal of tissue $\mathrm{pH}$ changes, is inevitable during the optimal therapy of AMI by prompt percutaneous coronary intervention (PCI). Working on this problem, the group of Hausenloy and Yellon ${ }^{10}$ in London discovered the RISK (Reperfusion Injury Salvage Kinases) cardioprotective pathway. Of major interest is that metabolic and molecular protection can go hand in hand. That concept leads to 
the proposal that insulin therapy, a promoter of optimal cardiac metabolic protection, can directly promote cardiac cell survival during reperfusion. ${ }^{11}$

From the evolutionary point of view it would have been inadequate to have only one molecular cardioprotective path. Thus another path was discovered, namely the SAFE (Survival Activating Factor Enhancement) pathway, that is the focus of our group under Sandrine Lecour. ${ }^{12}$ This path involves cytokine protection by low levels of tumour necrosis factor-alpha (TNF- $\alpha$ ) acting on a specific series of molecular events and leading to activation of transcription factor signal transducer and activator of transcription-3 (STAT-3).

\section{The jump from experiments to clinical certainty \\ Postconditioning by balloon inflation-reflation}

Can the basic laboratory data be clinically applied? In animals such as the baboon, the major part of myocardial metabolic damage occurs in the first hour. ${ }^{7}$ The first human studies with early intervention were with ischaemic postconditioning. That means that after coronary flow had been abruptly restored to the previously ischaemic myocardium by PCI, the intra-coronary balloon was blown up again to cause temporary ischaemia. The balloon was then released only to be briefly blown up again, a procedure repeated for five cycles, thereby causing a very significant reduction in infarct size as in the basic observations made by Thibault et al. ${ }^{13}$ With late reperfusion, after the crucial first 3 hours, the extent of reperfusion damage can be expected to be slight and the benefit of therapy aimed at reperfusion damage likewise slight or totally absent.

\section{Remote conditioning}

An even more interesting approach is remote conditioning, whereby intermittent occlusion-reperfusion of a limb acts at a distance to reduce cardiac reperfusion damage. First shown in patients with coronary bypass operations by Yellon's group, the concept has now been widely extended to involve other organs such as kidney and brain. This approach has found human application by the simple procedure of pumping up and down an ordinary blood pressure sphygmomanometer in the ambulance taking patients to hospital. ${ }^{14}$ The primary endpoint was myocardial salvage index at 30 days after primary PCI, measured, by myocardial perfusion imaging, as the proportion of the area at risk of cell death but salvaged by treatment. The area saved from cellular death was about $20-25 \%$. This procedure has no known side-effects and reduced the extent of the infarcted tissue; benefit was seen even in infarcts sustained by patients who were very rapidly transferred to the emergency room for PCI, following the onset of symptoms, by the efficient ambulance service that Denmark enjoys. The vexing question of how remote ischaemic conditioning works (cardioprotection at a distance) is still a matter of dispute; there are arguments for both humoral and nervous mechanisms.

\section{From near-certainty to wishful thinking}

Wouldn't it be wonderful if we could imagine that certain foodstuffs or beverages contain protective agents that promote our molecular ischaemic pathways? Although this is fanciful, nonetheless there is a possibility that certain components of wine, namely resveratrol and melatonin, may protect during reperfusion injury during the therapy of heart attacks. The impact on myocardial infarct size after coronary occlusion and reperfusion following administration of red wine, resveratrol, and melatonin to rats has been examined in our laboratory. ${ }^{15}$ Both resveratrol and melatonin gave substantial protection. The group of Sandrine Lecour has in the past suggested that the resveratrol content of red wine may, with only modest intake, reach blood levels high enough to be cardioprotective although that conclusion is only inferential and hypothetical. More recently melatonin has been discovered in red wine and also in white. ${ }^{15}$ Melatonin is commonly used by persons threatened by jet lag during air travel because it promotes a natural sleep rhythm (and may be one of the reasons why red wine with meals goes with a good night's sleep).

Speculatively, red wine ${ }^{16}$ is part of the French paradox with, however, many other factors contributing to the relative protection from myocardial infarction that the French enjoy, because of their traditional lifestyle (which regretfully is now fading). Overall, modest wine intake is of itself no panacea but rather only a small part of part of the healthy five-point lifestyle in which non-smoking and daily vigorous exercise, for more than 30 minutes, are the two top criteria. ${ }^{17}$ As fully argued in my recent book, Living Longer, Living Better, ${ }^{18}$ intense exercise not only acts by promoting preponderance of the vagus anti-adrenergic protective nervous system at rest, but also by stimulating the protective molecular paths.

Acknowledgements. Regretfully limitations of space have required omission of reference to excellent work by highly respected colleagues. The fuller text, with references, is available from the author.

Bing RJ, Siegel A, Ungar I, Gilbert M. Metabolism of the human heart. II. Studies on fat, ketone and mino acid metabolism. Am J Med 1954;16:504-515.

2. Shipp JC, Opie LH, Challoner D. Fatty acid and glucose metabolism in the perfused heart. Nature 1961;189:1018-1019.

3. Sodi-Pallares D, Testelli Mr, Fishleder Bl, et al. Effects of an intravenous infusion of a potassiumglucose-insulin solution on the electrocardiographic signs of myocardial infarction. A preliminary clinical report. Am J Cardiol 1962;9:166-181.

4. Oliver MF, Kurien VA, Greenwood TW. Relation between serum-free-fatty acids and arrhythmias and death after acute myocardial infarction. Lancet 1968;1:710-714.

Oliver MF, Opie LH. Effects of glucose and fatty acids on myocardial ischaemia and arrhythmias. Lancet 1994;343:155-158

Opie LH, Knuuti J. The adrenergic-fatty acid load in heart failure. J Am Coll Cardiol 2009; 54:16371646.

7. Opie LH, Bruyneel K, Owen P. Effects of glucose, insulin and potassium infusion on tissue metabolic changes within first hour of myocardial infarction in the baboon. Circulation 1975;52:49-57.

changes within first hour of myocardial infarction in the baboon. Circulation 1975;52:49-57.
Selker HP, Beshansky, JR Sheehan PR, et al. A double-blind randomized controlled trial of intravenous 8. Selker HP, Beshansky, JR Sheehan PR, et al. A double-blind randomized controlled trial of intravenous
glucose, insulin, and potassium (GIK) for acute coronary syndromes in emergency medical services. glucose, insulin, and potassium (GIK) for acute coronary syndromes in emergency medical services.
The IMMEDIATE (Immediate Myocardial Metabolic Enhancement during Initial Assessment and Treatment in Emergency Care) Trial. JAMA 2012; online 27 March 2012.

Treatment in Emergency Care) Trial. JAMA 2012; online 27 March 2012.
Opie LH, Lecour S, Mardikar H, Desphande G. Cardiac survival strategies: an evolutionary hypothesis 9. Opie LH, Lecour S, Mardikar H, Desphande G. Cardiac survival strategies: an evolutionary hypothesis
with rationale for metabolic therapy of acute heart failure. Transactions of the Royal Society South Africa 2010;65:185-189.

10. Hausenloy DJ, Yellon DM. Time to take myocardial reperfusion injury seriously. N Engl J Med 2008;359:518-520.

11. Fuglesteg BN, Suleman N, Tiron C, et al. Signal transducer and activator of transcription 3 is involved in the cardioprotective signalling pathway activated by insulin therapy at reperfusion. Basic Res Cardiol 2008;103:444-453.

12. Lecour S. Multiple protective pathways against reperfusion injury: a SAFE path without Aktion? J Mol Cell Cardiol 2009;46:607-609.

13. Thibault H, Piot C, Staat P, et al. Long-term benefit of postconditioning. Circulation 2008;117:10371044.

14. Bøtker HE, Kharbanda R, Schmidt MR, et al. Remote ischaemic conditioning before hospital admission, as a complement to angioplasty, and effect on myocardial salvage in patients with acute myocardial infarction: a randomised trial. Lancet 2010;375:727-734.

15. Lamont KT, Somers S, Lacerda L, Opie LH, Lecour S. Is red wine a SAFE sip away from cardioprotection? Mechanisms involved in resveratrol- and melatonin-induced cardioprotection. J Pineal Res 2011;50:374-380.

16. Opie LH, Lecour S. The red wine hypothesis: from concepts to protective signalling molecules. Eur Heart J 2007;28:1683-1689.

17. Opie LH. The five-point heart healthy lifestyle. SA Heart 2011;8:154-163.

18. Opie LH. Living Longer, Living Better. Exploring the Heart-Mind Connection. Oxford: Oxford University Press, 2011:31-54.

Accepted 1 February 2012. 